\title{
'What do our patients really want from us?': Ivestigating patients perceptions of the validity of the Chartermark criteria
}

\author{
M. L. Crossley, ${ }^{1}$ A. Blinkhorn, ${ }^{2}$ and M. Cox, ${ }^{3}$
}

Background The 'restructuring' of the NHS over the last decade has demanded a 'market oriented' service more receptive to the needs and priorities of 'clients'receiving health care. These changes have been important to the provision of dental health care in which there has been a similar need to provide increasingly patient and market oriented services. One of the ways in which quality care has been assessed within NHS Trusts is through the national 'Chartermark' award, which identifies national centres of excellence in health care and research.

Aim The aim of this paper is to assess whether patients themselves considered the criteria identified by the Chartermark award important in the provision of good quality dental services Method This is a pilot study consisting of a structured questionnaire conducted face-to-face with a 'convenience' sample of 46 patients.

Analysis Data were inputted into SPSS and thematic analysis was conducted on the data.

Results The Chartermark criteria relevant to patient involvement were divided into four main themes. The findings from this small pilot study suggest that in relation to dental care, although patients are interested in information on standards, performance and complaints, there is considerable disinterest in organisational and financial dimensions.

The 1990 NHS and Community Care Act symbolised the incep1 tion of radical changes in the NHS. It marked a process of radical restructuring in which emphasis was placed on improving primary health care and providing a more efficient and 'market oriented' service. The essential purpose was to develop competition amongst providers and to encourage them to provide the lowest cost and best quality service adapted to the specific 'needs' of local populations. In recent years, increasing emphasis has been placed on the fact that the definition and assessment of 'need' often differs between professional clinicians and patients ('clients' in the new market economy of health care). Accordingly, there have been concerted efforts to involve patients and the public more generally in discussions about need, treatment and patient priorities. Health authorities responsible for buying health care on behalf of local populations, have been encouraged by local politicians to work more closely with patients in identifying their needs and preferred options in health care. In this vein, it has been argued that the 'restructuring process' has increased the importance of the 'lay voice' and opened up possibilities for

${ }^{1^{*}}$ Lecturer in Behavioural Science, ${ }^{2}$ Professor of Oral Health, ${ }^{3}$ General Dental Practitioner, Turner Dental School, University of Manchester, Higher Cambridge Street, Manchester, M15 6FH

${ }^{*}$ Correspondence to: $M$ L Crossley

E-mail:michele.crossley@man.ac.uk

REFEREED PAPER

Received 06.07.00; Accepted 15.11.00

(C) British Dental Journal 2001; 190: 602-606 developing services more sensitive to the varied needs of NHS users. ${ }^{1}$ These developments are becoming increasingly important in dental care as dental services are expected to provide more patient and market oriented services. ${ }^{2}$

The national 'Chartermark' award was established a number of years ago to mark certain NHS Trusts as national centres of excellence in health care and research. ${ }^{3}$ There are ten criteria relevant to the Chartermark award. These include: setting standards; being open and providing full information; consulting and involving; encouraging access and the promotion of choice; treating all fairly; putting things right when they go wrong; using resources effectively; innovating and improving; working with other providers; and providing user satis-

Table I Summary of suggestions from feedback report

\section{Criteria I Set standards}

- Take action to publish your standards and performance in all areas throughout the Trust

- Take action to widen the information you provide in this area and explain the action taken to resolve any dips in performance

Criteria 2 Be open and provide full information

- Extend the membership of the Patient Information Group to include users of the service

- Review the Patient information handbook to include more information about the organisational structure, finance, standards, performance and complaints

Criteria 3 Consult and involve

- Publicise more widely the improvements to the service resulting from consultation with users and the wider community

Criteria 4 Encourage access and the promotion of choice

- Continue to develop new initiatives to ensure the service is easily accessible in a user-friendly way, and that responses are effective and prompt

Criteria 5 Treat all fairly

- Consider extending ongoing staff training in customer service to other Directorates or staff groups within the Trust

Criteria 6 Put things right when they go wrong

- Develop ways to ensure that users are aware of the overall complaints level, the action taken in response and particularly improvements that result

Criteria 7 Use resources effectively

- Seek ways to involve more users in value for money discussion and subsequent plans

Criteria 8 Innovate and improve

- Consider ways of demonstrating more clearly, for individual initiatives, the link between consultation and user input: the development of a project and user response to it.

Criteria 9 Work with other providers

- Establish systems for measuring and recording the effectiveness of co-operative arrangements

Criteria 10 Provide user satisfaction

- Continue to develop the survey system, perhaps through the design of an overall survey, in order to track trends more accurately

- Develop ways to improve users' awareness of survey results and the service's response to them 
Criteria

\section{Set standards}

QI Are you aware of how well the dental hospital's services meet nationally agreed criteria?

Q2 How interested would you be in this information?

2 Be open and provide full information

Q7 To what extent do you agree that:

Sufficient information is provided by the dental hospital in relation to particular treatments?

Sufficient information is provided by the dental hospital in relation to general patient care?

Q8 To what extent do you agree with the following statements: I would be interested in receiving information relating to the organisational structure of the dental hospital.

I would be interested in receiving information relating to the financial organisation of the dental hospital.

I would be interested in receiving information on how well the dental hospital meets nationally agreed standards and targets.

I would be interested in receiving information relating to how to complain if I experience problems with the treatment I receive.

3 Consult and involve (see also criteria 10 )

Q5 Are you aware of recent improvements that have been made to the dental services here as a result of the dental hospital consulting with patients?

\section{Encourage access and promote choice}

QII To what extent do you agree with the following statements: It has been easy for me to get treatment here. I have received treatment quickly here. I am satisfied with the services I have received. On the whole, the staff are helpful. On the whole, the staff here are friendly.

Q12 Have you received treatment in any other dental teaching hospital?

Q13 How would you rate the treatment provided here with the dental treatment you have received elsewhere?

\section{Put things right when they go wrong}

Q16 Do you have any suggestions for how the services provided at the dental hospital could be improved?

Q6 How interested would you be in the following information: Details of complaints made by other patients in relation to services provided by the dental hospital. How those complaints were dealt with. Improvements in services that were implemented as a result of patients complaints.

Q9 Have you ever had cause to make a complaint about the services/treatment you have received in the dental hospital?

Q10 If yes: Do you feel your complaint was adequately dealt with?

7 Use resources effectively

Q14 The dental hospital has a limited budget and has to weigh up financial decisions regarding where to allocate its resources very carefully. Do you think patients should have a say in these decisions?

Q15 Would you personally be interested in being involved in decisions about where to allocate financial resources?

10 Provide user satisfaction

Q3 Are you aware of how satisfied other patients have been with the services provided in the dental hospital?

Q4 How interested would you be in knowing this?
Response categories

$\mathrm{Y} / \mathrm{N}$

Very/Moderately/Not

Agree/Disagree/Undecided

Agree/Disagree/Undecided

Agree/Disagree/Undecided

Agree/Disagree/Undecided

Agree/Disagree/Undecided

Agree/Disagree/Undecided

$\mathrm{Y} / \mathrm{N}$

Agree/Disagree/Undecided Agree/Disagree/Undecided Agree/Disagree/Undecided Agree/Disagree/Undecided Agree/Disagree/Undecided

$\mathrm{Y} / \mathrm{N}$

Better/The same/Worse

Open ended

Interested/Not interested/Undecided Interested/Not interested/Undecided

Interested/Not interested/Undecided

$\mathrm{Y} / \mathrm{N}$

Open ended

Very/Moderately/Not 
Table 2 Percentage responses to questions addressing criteria I, 'Setting Standards'

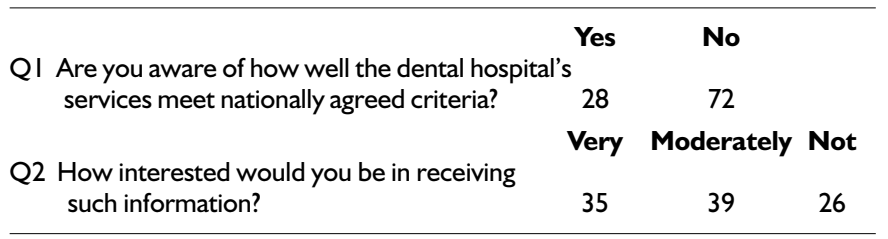

faction. As is clear from this list, many of these criteria relate to greater patient involvement in decision making and health care, in congruence with the attempt to provide a more 'market oriented' healthcare system. The Central Manchester Healthcare NHS Trust was set up as one of the first wave NHS Trusts and has been awarded the national 'Charter Mark' for excellence. The Trust comprises a number of medical hospitals within the area and the dental hospital.

The maintenance of the Chartermark award remains dependent on the continued achievement of the ten Chartermark critiera. Accordingly, in 1999, the health services provided across the Trust were evaluated by assessors in terms of their adherence to the Chartermark criteria. This resulted in the production of a feedback report which provided suggestions for improvements in services in relation to the ten Chartermark criteria (see Table 1).

Before acting on these suggestions in the dental hospital, however, it was considered a good idea to consult patients in order to assess what they actually thought about the various criteria constituting the Chartermark definition of excellence. The aim of this study was therefore to assess how relevant patients thought the various criteria were to services provided in the dental hospital. Are the criteria and the suggested improvements getting to grips with what patients actually want and expect of their dental services? The overall objective of the study was therefore to determine whether the concerns of the Trust highlighted in their feedback report document, are perceived by patients as relevant to their dental and health care needs.

\section{Method}

A questionnaire was constructed addressing seven of the Chartermark criteria (Figure 1). Criteria 5, 8 and 9 were excluded because the suggestions incorporated in the feedback report included activities and training which were to take place at the more 'structural' level of the service. For instance, criteria 5 (treat all fairly) entailed extending staff training in customer services, criteria 8 (innovate and improve) involved the development of structured programmes to demonstrate links between consultation and user input, and finally, criteria 9 (working with other providers) entailed systems for measuring and recording the effectiveness of co-operative arrangements. All of these criteria involved changes in services in which it was unlikely that patients would be able to assess adequately.

Possible responses to the questions asked involved a mixture of closed and open ended categories in order that data capable of both quantitative and qualitative analysis could be obtained. As this was a pilot study, it was decided that the questionnaire should be completed face-to-face with an interviewer in order that potential problems could be highlighted. A small pre-pilot study (with eight patients) was conducted to identify any problems and concerns with the interview schedule. Some ambiguous wording was identified and the interview schedule was revised accordingly.

The nature of the sample was a 'convenience sample' in which as many patients as possible were interviewed during a two-week block. This included patients from the five main departments of the dental school: prosthodontics, periodontology, conservation, oral medicine and oral surgery. In addition, patients in dental casualty (Dcas) were interviewed. The departments of paediatrics and orthodontics were excluded due to the atypical nature of the patients seen in these clinics. Initially, the idea was to collect data by

Table 3 Percentage responses to questions addressing criteria 2, ' $\mathrm{Be}$ open and provide full information'.

Agree Disagree Undecided

Q7 To what extent do you agree that:

i) Sufficient information is provided by the dental hospital in relation to particular treatments?

ii) Sufficient information is provided by the dental hospital in relation to general patient care?

Q8 To what extent do you agree with the

following statements:

i) I would be interested in receiving information re organisational structure?

ii) re financial organisation

iii) re how well hospital meets nationally agreed targets

iv) re how to complain if poor treatment

\section{6}

48

26

andomly allocating an afternoon or morning to each of the departments. However, this created problems because some of the departments were not open when the researcher was available for data collection and it quickly became apparent that it was very difficult to collect data both when the department was running on time and when it was running late. Accordingly, the researcher simply attempted to maximise the amount of people interviewed in the limited period of time. Patients were approached before their appointment. A full introduction was given and the purpose of the questions and the research explained. Assurance was provided that information given by the patient was confidential and would not affect their treatment. An enquiry was made as to what time their appointment was, and an estimation of how long the interview would take. Verbal consent was then obtained.

A total of 46 patients were interviewed. Sixteen (35\%) of these were attending the prosthetic department, 4 (9\%) oral medicine, $5(11 \%)$ oral surgery, $13(28 \%)$ conservation and $8(17 \%)$ Dcas. Twenty eight of the patients were women and 18 were men. Forty $(87 \%)$ of the patients were White, one was Afro-Caribbean and four were Asian. Only one patient declined to be interviewed and one interview schedule remained incomplete because of the patient's appointment time starting.

\section{Results}

Patients' responses to the questionnaire are presented in Tables 2-7.

\section{Discussion}

Although this questionnaire was set up to address the specific Chartermark criteria it quickly became clear that there was a great deal of overlap between these categories. Accordingly, as the analysis proceeded, it became useful to characterise more general dimensions manifest within the Chartermark criteria and emerging from the responses provided by participants. These included the four dimensions depicted in Table 8 . Patient interest in these dimensions is indicated to the right hand side of the table. Each of these four themes will now be discussed in more detail.

In relation to the first theme, information in relation to national standards and treatments, it became clear that patients expressed interest in such issues. When asked how interested they would be in receiving information on the degree to which the dental hospital conformed to nationally agreed standards and targets, $74 \%$ expressed interest ranging from 'very' to 'moderately'. By contrast, only $28 \%$ said they actually were aware of how well the dental hospital's services met nationally agreed criteria. The majority of these patients were from the prosthetic department. This could be due to either a poster in the waiting room or due to the nature and age of this group of patients. Having said that, over the course of this 
Table 4 Percentage responses to questions addressing criteria 3, 'Consult and involve' and criteria 10, 'provide user satisfaction'.

\begin{tabular}{lcc}
\hline Items & Yes & No \\
\hline Q3 Aware of satisfaction of other patients? & 30 & 67 \\
Q5 Aware of recent service improvements? & 30 & 65
\end{tabular}

Table 5 Percentage responses to questions addressing criteria 4, 'encourage access and promote choice' *.

\begin{tabular}{lccc}
\hline Items & Agree & Disagree & Undecided \\
Easy to get treatment & 89 & 4 & 4 \\
Received treatment quickly & 72 & 17 & 6 \\
Satisfied & 89 & 7 & 2 \\
Staff helpful & 93 & 2 & 2 \\
Staff friendly & 89 & 2 & 6 \\
\hline
\end{tabular}

* Only $9 \%(n=4)$ respondents had received dental treatment in other dental hospitals compared to general dental treatment received elsewhere, $35 \%$ thought the treatment received here was 'much better', 33\% 'the same' and 4\% 'much worse'. Responses to question 16 were open ended and are addressed further in the discussion.

research, the dental hospital did have a series of posters placed around the building giving information about various aspects of the Patient's Charter and not turning up to appointments. However, only one patient out of 46 said they had actually seen this poster! This suggests that different ways of transmitting this information may be required.

On the whole, the majority of patients interviewed were satisfied with the amount of information they received both in relation to particular dental treatments (56\%) and more general patient care at the dental hospital (48\%). Many of the patients interviewed mentioned an information booklet sent out to them which included information such as telephone numbers, departments, opening times and car parking. Having said that, however, $22 \%$ of patients disagreed that they had been given sufficient clinical information and wanted more details on their treatment. A typical example was one respondent who said that he would have appreciated 'some sort of treatment plan giving some sort information so you know what to expect and how long the treatment plan is going to take'.

In terms of the second theme, accessible and efficient service delivery, the majority of patients agreed that they had received dental treatment easily $(89 \%)$, quickly $(72 \%)$, the staff were helpful (93\%), friendly (89\%) and patients were, on the whole, satisfied $(89 \%)$. Of those who were dissatisfied, however, and others asked for their suggestions on how to improve service delivery, one recurring theme was the need to improve the waiting times of patients,

Table 6 Percentage responses to questions addressing criteria 6, 'put things right when they go wrong'**

Items Interested Not interested Undecided

Q6i Complaints made by other patients

Q6ii How complaints are dealt with

61

Q6iii Improvements after complaints

67

37

33

28

2

2

** Only one respondent had ever made a complaint about services/treatments.

Table 7 Percentage responses to questions addressing criteria 7, 'use resources effectively'

\begin{tabular}{|c|c|c|}
\hline & Yes & No \\
\hline $\begin{array}{l}\text { QI4 Do you think patients should have a say in financial } \\
\text { decisions regarding resource allocation? } \\
\text { QI5 Would you personally be interested in getting involved }\end{array}$ & 35 & 61 \\
\hline in decisions about allocation of financial resources? & 13 & 87 \\
\hline
\end{tabular}

especially in dental casualty. Another problem mentioned by a number of patients was that their treatment felt impersonal and lacking in continuity, often because they were treated by different students during the course of their treatment. Another problem related to reception staff who were sometimes 'a little off-hand'.

In terms of the third theme, complaints and user satisfaction, only $30 \%$ of patients said that they were aware of how satisfied other patients had been with the services received in the dental school. Likewise, only $30 \%$ were aware of recent improvements made as a result of consultation with patients. By contrast, the majority said they would be interested in receiving information about other patients' satisfaction (65\%), other patients' complaints (61\%), how to complain themselves if they experienced poor treatment (76\%), how complaints have been dealt with $(67 \%)$ and improvements made in the wake of such complaints (70\%). Although the dental school obviously had a complaints procedure, the leaflets outlining this information were only available on request. During the month of October 1999 only two complaints were received. Only one of the participants involved in the research had made a complaint.

Finally, in terms of the fourth theme 'consultation and involvement re financial and organisational issues', unlike interest in relation to treatment and general service delivery, respondents expressed a general disinterest in financial and organisational aspects of the service. For instance, the majority (48\%) expressed a disinterest in receiving information relating to organisational dimensions of the dental hospital, whilst $56 \%$ did the same re financial aspects. The majority stated that financial decisions should be left in the hands of administrators and clinicians and the general consensus was that patients would bias the financial decisions to their benefit.

Likewise, $61 \%$ of respondents did not think it was appropriate for patients to be more involved with decisions regarding resource allocation. And when asked if they personally were interested in getting involved with such decision making processes, only $13 \%$ responded affirmatively. The following were typical of the comments made: 'Clinicians have more experience and patients would only say what would be good for their own personal needs'; 'I think the patients would be very selfish and would only be thinking of their own treatment needs'; 'Patients wouldn't know enough about treatment'; 'Patients don't necessarily know the ins and outs; 'Nothing would be done if all patients had a say'; 'I wouldn't trust people with that responsibility'.

These findings are consistent with other studies on patient involvement in priority setting in which it has been found that patients remain unconvinced that they have a legitimate role to play in determining the allocation of limited financial resources. ${ }^{4}$ Likewise, Milewa questions the degree to which 'the public' are interested in discussing health care priorities. People often express a reluctance to become involved in such debates and any attempt at 'public participation' is based on the implicit, often unexplored assumption that the individuals concerned already hold apposite opinions and that they view such opinions as legitimate and reasonable. ${ }^{5}$ Milewa argues that public involvement in the identification of health care priorities is considerably more complex than the

Table 8 Four more general dimensions of the Chartermark criteria and patient interest in these dimensions

\begin{tabular}{lcc}
\hline Dimension & $\begin{array}{c}\text { Patient } \\
\text { interest }\end{array}$ & $\begin{array}{c}\text { Is enough } \\
\text { being done? }\end{array}$ \\
\hline $\begin{array}{l}\text { Information re national standards and } \\
\text { treatments (criteria I and 2) }\end{array}$ & Yes & No \\
$\begin{array}{l}\text { Accessible and efficient service delivery (criteria 4) } \\
\text { Complaints and user satisfaction (criteria 6 and 10) }\end{array}$ & Yes & Yes but... \\
$\begin{array}{l}\text { Consultation and involvement re organisational } \\
\text { and financial issues (criteria 3 and 7) }\end{array}$ & No & No \\
\hline
\end{tabular}




\section{RESEARCH external relations}

contemporary political rhetoric suggests. Accordingly, the current political interest in gauging 'local voices' may be 'at best, a preliminary exercise designed to raise popular awareness of the need to prioritise, rather than — as has been maintained, a means by which to actively involve people in the determination of health care priorities. Finally, it is important to consider the limitations of this study. The respondents interviewed did not comprise a representative sample, but simply a 'convenience sample'. Although their views represent an interesting snapshot of patients attending the dental school, they cannot be taken as representative of the views of patients attending the dental school or dental services more generally. In addition, it is likely that the views of patients receiving dental care may be different to those receiving different (non-dentally related) health care. The next stage of this investigation will therefore be to conduct a larger scale study in which patients are randomly selected from different departments in the dental school and patients receiving different types of health care, as a means of assessing the generalisability of these findings.

\section{Conclusion}

The 'restructuring' of the NHS has aimed to create a more 'market led' service responsive to the varied needs and priorities of 'clients'. These developments are becoming increasingly important in dental care as dental services are expected to provide more patient and market oriented services. An important dimension of the 'Chartermark' award, established as a means of demarcating centres of excellence in health care and research, relates to patient involvement in health-care and decision making. This paper consulted patients as a means of establishing whether the criteria regarding patient involvement were perceived by patients themselves as relevant to their dental care. Chartermark criteria relevant to patient involvement were divided into four main themes:

1 Information re national standards and treatments

2 Accessible and efficient service delivery

3 Complaints and user satisfaction

4 Consultation and involvement re organisational and financial issues.

The findings of this small survey suggest that in relation to dental care, although patients are interested in information on standards, performance and complaints, there is considerable disinterest in organisational and financial dimensions. Although this small scale study needs to be expanded upon, it is clear that these results are important in assessing the relevance of the Chartermark criteria to patients themselves.

1 Crossley M L. Rethinking Health Psychology. Buckinghamshire, Milton Keynes: Open University Press, 2000.

2 Bradnock G, Pine C. Delivery of oral health care and implications for future planning. in Pine, C. (ed). Community Oral Health. Oxford: Wright Press, 1997.

3 Central Manchester NHS Trust. Chartermark Awards 1999. Feedback Report. Manchester: Central Manchester NHS Trust, 1999.

4 Dicker A, Armstrong D. Patients views of priority setting in health care: an interview survey in one practice. BMJ 1995; 311: 1137-9.

5 Milewa T. Community participation and health care priorities: reflections on policy, theatre and reality in Britain. Health Promotion International 1997; 12: 161-168. 